\title{
Teachers' Perceptions of Physical Education Teaching Barriers at Elementary Schools
}

\author{
Gita Febria Friskawati*, Akhmad Sobarna \\ Physical Education and Health Dept. \\ STKIP Pasundan Cimahi \\ *gita032@gmail.com
}

\author{
Mesa Rahmi Stephani \\ Faculty of Sport and Health Education \\ Universitas Pendidikan Indonesia
}

\begin{abstract}
The purpose of this study was to examine what elementary school teacher perception of Physical Education's (PE) is teaching barriers such as institutional barrier, teacher related barrier and student related barrier. Survey methods used in this research. A total of 48 elementary teacher (40 men and 8 women) take a part of this study. Sampling taken through convenience sampling from elementary teachers at Cimahi. Data collected through 5-point Likert-type questionnaire of teacher's perception of Physical Education's teaching barriers. All of samples was willing to be involved in this study. Finding show that institutional barrier become the major barrier to teaching PE at elementary school. An awareness of these barriers has implications for physical education teaching in the elementary school environment so, teachers have to overcome this barriers with using modification in every teaching learning process.
\end{abstract}

Keywords: physical education, teaching barriers, teacher's perception

\section{INTRODUCTION}

Providing quality physical education in elementary school is very important. It's because childhood are critical periods for the acquisition of healthy lifestyles. Physical activity levels have to be increased in this periods. Physical activities that carried out regularly by children will contribute to the development of psychomotor, social and cognitive abilities [1]. Physical activity will increase with the right facilities and flexible according to the ability of children [2,3]. The availability of facilities and equipment to support physical activities for children who are suitable can also create a pleasant atmosphere for children. It's because they feel comfortable and in accordance with their abilities [4]. Having an adequate amount of sport and exercise equipment that is in good condition and appropriate for children's sizes is also likely to increase physical activity opportunities during PE class sessions.

Physical education programs can meet students' learning needs for motion and provide new movement skills for them. The goal, physical education programs was to increase active lifestyle for students as well as for their holistic growth and development [5]. Physical education also helps children to improve social skills, self-concept and allows an opportunity to experience success in a unique learning environment [6,7]. So many benefit can give by physical education at school.
Unfortunately, there are some many barriers in teaching learning physical education that can impact quality teaching. The barriers perceived by teachers can impact on students' participation in physical education program at school and physical activity were examine [8]. Teachers believe in the benefits of physical education but would rather teach other subjects due to a lack of confidence, time and equipment [9]. Another research show that major barriers to teaching physical education: lack of resources such as teacher's guide, lack of time, lack of support from other teachers and lack of adequate training for physical education's teacher [10]. But, the largest barrier for Quality physical education in primary schools is the qualifications and preparation of teachers [11].

The barriers that can influence quality teaching in physical education was identify, such as institutional barriers, teacher related barriers and student related barriers [10,12]. The order of institution-related barriers from strongest to least impacting were 1) lack of time for held physical education, 2) lack of departmental assistance, 3) lack of money for get physical education's tools and equipment's, 4) inadequate facilities and equipment for each students, and 5) class size too large $[6,11]$. The teacher related barriers were: 1) possessing low levels of confidence or interest in teaching physical education, 2) being unable to provide safely planned and structured lessons, 3) having had personal negative experiences in physical education and lacking training, knowledge, expertise and 4) qualifications to provide physical education $[6,13,14]$. The student related barriers were: 1) Student unwillingness to participate in physical education programme, 2) a dislike of activity that include to the programs, 3) a lack of understanding of the benefits of physical activity for their life and 4) a decline in student interest in physical education at schools [15-18].

Physical education programs can be impact to student directly if there was no barriers in teaching learning process. So, the barriers have to avoid and teacher have to overcome all of barriers such as institutional barriers related, students barriers related and teachers related. This research may highlight perceives of physical education teacher's barriers to providing quality physical education too regarding institutional barriers, teacher related barriers and student related barriers.

\section{METHOD}

The aim of this research was to examine what elementary school teacher perception of physical education is teaching 
barriers such as institutional barrier, teacher related barrier and student related barrier. Survey methods used in this research. A total of 48 elementary teacher ( 40 men and 8 women) take a part of this study who was ready to fill up the questionnaire. Sampling taken by convenience sampling. Data collected through 5-point Likert-type questionnaire from Morgan and Hansen [6]. The questioner that used relatively short questionnaires that shared with google form. Simple analyses with percentage used to be describe how teacher's perception about the institutional barriers, teacher related barrier, and student related barriers appearance in physical education learning process.

\section{RESULTS AND DISCUSSION}

The closed-ended survey data for each question quality physical education at elementary school. Using percentage, there was describe amount of three of barriers to providing teaching learning physical education. Analysis consisted of frequency statistics including means, standard deviations and percentages for all variables, the barriers experienced by physical education teachers as well as those perceived by teachers to be experienced by students inside the school environment [7]. Figure 1 show the result of data using percentage.

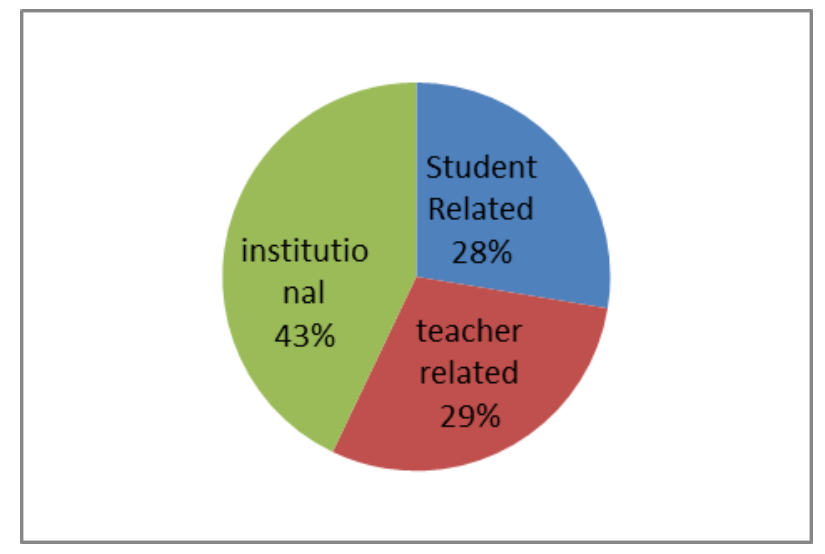

Fig. 1. Percentage of barriers providing quality phusical education at elementary school.

Data show that $28 \%$ barriers are from student related barriers, 29\% barriers are from teacher related barriers and $43 \%$ barriers are from institutional barriers. The barriers to the provision of physical education were found to be largely institutional, although two-thirds of respondents recognised their own difficulties in engaging students when teaching as potential obstacles to student participation. Adequate resources may reduce the proportion of class time needed for management and thereby increase opportunities for children to be physically active. For example, large class sizes resulting from high student-to-physical educator ratios may require that more time be devoted to activities such as taking attendance and transitioning from one activity to the next [19].

Institutional barriers as those factors that are beyond teachers' control, while teacher-related barriers result from teachers' behaviours. In addition, student-related barriers have been shown to inhibit the delivery of quality PE [20]. Examples of institutional barriers include lack of time, marginalization of the subject, timetabling, and lack of resources. Lack of training and confidence are some teacher-related barriers to teaching PE. Lack of student interest and motivation are student-related factors that often impede the teaching of PE.

Insufficient curriculum time allocation, perceived inferior subject status, insufficient competent qualified and inadequately trained teachers (particularly in primary schools), inadequate provision of facilities and equipment and teaching materials frequently associated with under-funding, large class sizes and funding cuts and, in some countries, inadequate provision or awareness of pathway links to wider community programmes and facilities outside of schools [21].

\section{CONCLUSIONS}

Some of these barriers can be overcome by teacher with well planning teaching learning process. But, in another hand teacher can't gain access to funding for equipment, facilities, teaching spaces and curriculum positioning by self, its necessary to discussing and lobbying with strong leadership at school who make the policy. The major barrier in this research was institutional barrier so, teacher can make some modification at equipment that used in teaching learning process to overcome this barrier. Not only at elementary but also secondary and high school teachers should be aware and avoid these barriers to providing quality teaching in physical education.

Data were collected with self-report, teachers may not have accurately answer according to physical education condition in theirs schools. Teachers may have tend to claim that institutional or student related barriers had a greater influence on student's perception instead of teachers related. It's necessary to know how student's barrier perceptions barriers about teaching learning physical education that correlate with teacher barriers and effective teaching in future research.

\section{REFERENCES}

[1] Martin, "PE2GO: program evaluation of a physical activity program in elementary schools," Journal of Physical Activity and Health, vol. 7, pp. 677-684, 2010.

[2] J.F. Sallis, M. F. Johnson, K. J. Calfas, S. Caparosa, J. F. Nichols, "Assessing perceived physical environmental variables that may influence physical activity,” Res Q Exerc Sport, vol. 68(4), pp. 345-351, 1997.

[3] M.L. Humbert, K. E. Chad, M. W. Bruner, "Using a naturalistic ecological approach to examine the factors influencing youth physical activity across grades 7 to 12 " Health Educ Behav, vol. 35(2), pp. 158, 2008.

[4] Shelly, "Low-cost and scalable classroom equipment to promote physical activity and improve education," Journal of Physical Activity and Health, vol. 12, pp. $1259-1263,2015$.

[5] P. J. Naylor and H. A. McKay, "Prevention in the first place: schools a setting for action on physical inactivity," Journal of Sports Med, vol. 43(1), pp. 10-3, January 2009.

[6] P.J. Morgan and V. Hansen, "Physical education in primary schools: classroom teachers' perceptions of benefits and outcomes," Health Education Journal, vol. 67(3), pp. 196-207, 2008.

[7] Filazoğlu-ÇOKLUK, Gülşen, "The effects of physical education and sports on the self-concept of the children with mild mental disabilities," 
teachers' beliefs," Journal of Teaching in Physical Education, vol. 21(2), pp. 145-161, 2002.

International Journal of Science Culture and Sport (IntJSCS), Special Issue 3, 2015.

[8] K.A. Jenkinson, and A. C. Benson, "Barriers to providing physical education and physical activity in victorian state secondary schools," Australian Journal of Teacher Education, vol. 35(8), 2010.

[9] Philip J Morgana and Vibeke Hansena, "Physical education in primary schools: classroom teachers' perceptions of benefi ts and outcomes," Health Education Journal, vol. 67(3), pp. 196-207, 2008.

[10] Seidu Sofo and Eugene F. Asola, "Barriers to providing quality physical education in primary schools in ghana," IOSR Journal of Sports and Physical Education (IOSR-JSPE), vol. 3(3), pp. 45-48, 2016.

[11] K.B. Bevans, L.-A.Fitzpatrick, B. M. Sanchez, A. W. Riley, and C. Forrest, "Physical education resources, class management, and student physical activity levels: a structure-process-outcome approach to evaluating physical education effectiveness," Journal of School Health, vol. 80(12), pp. 573-580, 2010.

[12] C.M. Mowling, S.J. Brock, K.K. Eiler and M.E. Rudisill, "Student motivaion in physical education," Journal of Physical Education, Recreation \& Dance, vol. 75(6), pp. 40-51, 2004.

[13] K. De Corby, J. Halas, S. Dixon, L. Wintrup, and H. Janzen, "Classroomteachers and the challenges of delivering quality physical education," The Journal of Educational Research, vol. 98(4), pp. 208220, 2005.

[14] P. Xiang, S. Lowy, and R. McBride, "The impact of a field-based elementaryphysical education methods course on preservice classroom
[15] S. Dagkas, and A. Stathi, "Exploring social and environmental factors affecting adolescents' participation in physical activity," European Physical Education Review, vol. 13(3), pp. 369-384, 2007.

[16] S.D.Boyle, G.L. Jones, and S.J. Walters, "Physical activity among adolescents and barriers to delivering physical education in Cornwall and Lancashire, UK: a qualitative study of heads of PE and heads of schools," BMC Public Health, vol. 8, pp. 273-281, 2008.

[17] L.B. Sherar, N.C. Gyurcsik, M.L. Humbert, R. F. Dyck, S. Fowler Kerry and A. D. G. Baxter-Jones, "Activity and barriers in girls (8-16 years) based on grade and maturity status," Medicine \& Science in Sports \& Exercise, vol. 41(1), pp. 87-95, 2009.

[18] F. Trudeau, and R.J. Shephard, "Contribution of school programmes to physical activity levels and attitudes in children and adults," Sports Medicine, vol. 35(2), pp. 89-105, 2005.

[19] David A. Kinnunen and Dawn K. Lewis, "A case study of preservice physical education teachers' Attitudes toward and Perceived Barriers to Quality Physical Education," Journal of Education and Practice, vol. 4(8), 2013.

[20] Timothy Lynch1 and Gregory J. Soukup, "Primary physical education (PE): School leader perceptions about classroom teacher quality implementation," Lynch \& Soukup, Cogent Education (2017), vol. 4, p. 1348925, 2017.

[21] K. Hardman and J. Marshall, "Update on the state and status of physical education world-wide," 2009. 